\title{
'Debating' the Merits of Clickers in an Academic Library
}

\author{
Bobbie L. Collins, Rosalind Tedford, H. David Womack
}

$\mathrm{T}$ echnological innovations offer an opportunity for librarians to "enhance teaching methods and meet the demand for student-centered, active learning classroom strategies." Librarians are constantly searching for new pedagogical approaches to incorporate into their classroom presentations. In an attempt to make library instruction more interactive and to include active learning modules that motivate the student audience, librarians are developing creative programs to teach information literacy skills. $^{2}$ As part of this process, librarians are also identifying new tech devices, such as audience response systems, that may have pedagogic potential.

Audience response systems, or clickers, are gaining popularity on many college campuses as a tool to gauge students' understanding of the material being presented during a lecture or similar session. In an article describing new high-tech products, Gary Roberts predicted that screencasting software and classroom response systems "will eventually become essential tools for dynamic educators." 3

\section{Getting Started with Clickers at the ZSR Library}

In 2006, Lynn Sutton, the Director of the Z. Smith Reynolds Library at Wake Forest University, and Rosalind Tedford, the Information Literacy Librarian there, began discussing the merits of having an audience response system both for use in library instruction and for gaining feedback in library staff meetings. Rosalind attended a Blackboard World ${ }^{\circledR}$ conference where all three of the major vendors of these systems were exhibitors. The library was looking for a technology with a low learning curve that could readily be adopted by a wide range of library staff, not just those more technologically adventurous. After interviewing all three vendors and watching demos of their products, we invited a representative from Turning Point ${ }^{\circledR}$ to Winston-Salem to give a sales demo of the clicker software to the library staff.

TurningPoint ${ }^{\circledR}$ was chosen because it integrates completely with Microsoft's PowerPoint software, a program already used heavily by library staff. Instructors simply insert TurningPoint slides into existing PowerPoint presentations and set the kind of feedback they wish to see. Questions can be posed as True/False, Multiple Choice/Multiple Answer, or Likert-style, and results can be displayed as bar graphs, pie charts, or doughnut charts. While more advanced functions are available, an instructor does not need to know them in order to make quick use of the software. Using a handheld device, students respond to questions as they see them displayed in the PowerPoint presentation. Students and instructors then get immediate feedback on the screen in the form of graphs of user responses.

After watching the demonstration, library instructional staff were impressed with TurningPoint ${ }^{\circledR}$. The idea of using clickers in the library's instructional program appeared promising to most of the staff, but some were concerned about the amount of preparation required to implement this technology into existing library instructional classes. In deciding whether to invest time and money in clicker technology, staff pondered other questions: What would be the benefits of using the clickers? Would clickers eat up precious class time? And more importantly, how would students respond to this technology? Would it provide reliable and comprehensive feedback for both instructors and students?

After considering the pros and cons of the clicker technology, the Information Literacy Librarian recommended purchasing 30 clickers and one receiver. The clickers were tested in two sections of the library's for-credit Information Literacy class (LIB100) in the Spring of 2007. The students loved them and the clickers were such a popular item among library staff for a variety of purposes that in the Summer of 2007 an additional 30 clickers and two receivers were purchased for library use. This article will discuss the logistics of our implementation and discuss the ways we use clickers at Wake Forest. Along the way we will look at successes, failures, and lessons learned and provide tips for other libraries interested in this interactive technology.

\section{Training and Support for the Clickers}

During the summer of 2007, once the decision was made to use the clickers across the library, several classes were given to show staff how to use the software with PowerPoint. The software was loaded on each person's machine before class time, so that the class could be focused on using the software. For people who were not able to attend the classes, one-on-one help was given by the Information Literacy Librarian and Giz Womack, the Manager of Technology Training, on an as-needed basis. Although the software is easy to install and use, not unexpectedly some glitches were encountered, especially in synchronizing receivers and computers. Those glitches were worked out eventually, however, and technical support for the clickers has been minimal. Additional classes in using the clickers will be taught again in the summer of 2008 for new staff members and those who use the software infrequently.

\section{Managing the Clickers}

Early on it became apparent that a booking system was needed to manage the clickers. With several sections of the LIB 100 credit course and other library instruction classes being offered throughout the day, a central location for picking up and dropping off the clickers was essential. The 60 clickers were split into three sets, each with its own carrying case, 20 clickers, one receiver, and several replacement batteries. We use a Microsoft Outlook resource calendar to book the clickers. To reserve the clickers for a class or meeting, a staff person checks an online calendar to make sure that a set of clickers is available on the date(s) needed and then requests a reservation from the IL Librarian or the Manager of Technology Training. If the class size is more than 20 students, the instructor can book two sets of clickers. Along with figuring out a booking system, the IL Librarian had to determine a safe and accessible location for housing the clickers. Presently, the IL Librarian's office houses the clickers and so far the booking system is working. 
Putting the Clickers into Action with LIB 100 Students

Because we knew that students like using clickers "for immediate feedback, knowledge-checking, in-class surveys, group work, and other engaging activities," we immediately looked for places to incorporate them into our instructional program.

At the ZSR Library we teach a for-credit elective class for undergraduates and we are always in the market for ways to make that class engaging and interactive for the students and instructors alike. The clickers seemed like a perfect opportunity for us to do this. In January and February of 2007 the Information Literacy Instructor added TurningPoint ${ }^{\circledR}$ 'clicker' slides to a few of the PowerPoint presentations that were used by many instructors. Then, she and our Technology Training Specialist used the clicker presentations in the two sections of LIB100 that they taught in the late Spring. The course evaluation given at the end of the class included a question about how the students felt about the clickers. Their responses were almost universally positive:

- I think the electronic polling tools were instrumental in creating participation in the class structure.

- I liked the clickers, it's a good way of letting students voice their opinions quickly.

- I really enjoyed the use of clickers in the class. While probably not necessary, I do feel like they improved my overall classroom experience AND my ability to participate regularly.

- ...the clickers were fun. I think the class responded more than they would have without the clickers.

- I really enjoyed the clickers, I thought they were a clever idea and a good way to keep class interesting with student participation.

- The clickers were great-they encouraged student participation, they were fun, they were exciting.

- The clickers were a great idea though they didn't always work. I found them fun. I also feel as though they offered a way for all students to contribute to class discussions while eliminating that fear of raising your hand and feeling singled out. I wish all professors used this.

In addition to these advocates, however, there were a few students who were not as enthusiastic. Statements like, "I thought the clickers were okay but I feel like everything these days is a poll. Everybody wants to know what everybody else thinks, so it gets sort of annoying but they weren't too bad," and "The clickers were a gimmick, they did next to nothing and just took up time," made us aware of the fact that not all students will respond positively to this technology in the classroom.

Bolstered by the positive feedback, the Information Literacy Librarian took the summer to rework most of the class PowerPoint presentations to include clicker slides. They were then presented to the LIB100 instructors and made available to them over the campus network. Instructors could copy the presentations to their hard drives and alter them as needed. The TurningPoint ${ }^{\circledR}$ training empowered instructors to create their own presentations to cover the material in the way they saw fit. The Information Literacy Librarian and the Technology Training Manager were available to the instructors to help troubleshoot problems before, during, or after their classes.
Overall, the clickers have not changed what we teach in our LIB100 classes as much as they have changed how we teach. The students are more engaged in the content when they get immediate feedback, and we have found that better classroom discussions ensue. The clickers are generally not used for graded assignments, but rather to point out to students what they do and do not already know about doing research and to get them to use searching skills on the fly to answer questions. When they all answer a question incorrectly, they tend to pay more attention when you are providing the answer. In future semesters we hope to harness some of the advanced features of the clickers to do more competitive activities where teams can compete on questions and where we can track individual answers. But for now the students seem to like being able to respond in class with this technology and certainly seem to think it makes the class more interesting.

\section{Debating the Merits of Clickers with High School Students}

After watching a demo of TurningPoint ${ }^{\circledR}$, it became clear to the lead instructor that clickers could be used to check for student comprehension in the Wake Forest University summer debate workshops for high school students. As part of the learning experience, debaters participate in a hands-on library session which includes an orientation to the library's online catalog, databases, and other electronic resources. In the summer of 2007, two groups of debaters (total of 37 students) came to the library's computer lab for a two-hour session on researching their debate topics. At the beginning of class, the students were instructed on using the clickers and were given five practice questions:

- Have you ever used a clicker or an electronic classroom response system?

- If yes, where did you use a clicker?

- What part of the country are you from?

- When you return to your school in the fall, will you be a freshman, sophomore, junior, senior, or college bound?

- Have you attended a WFU debate workshop?

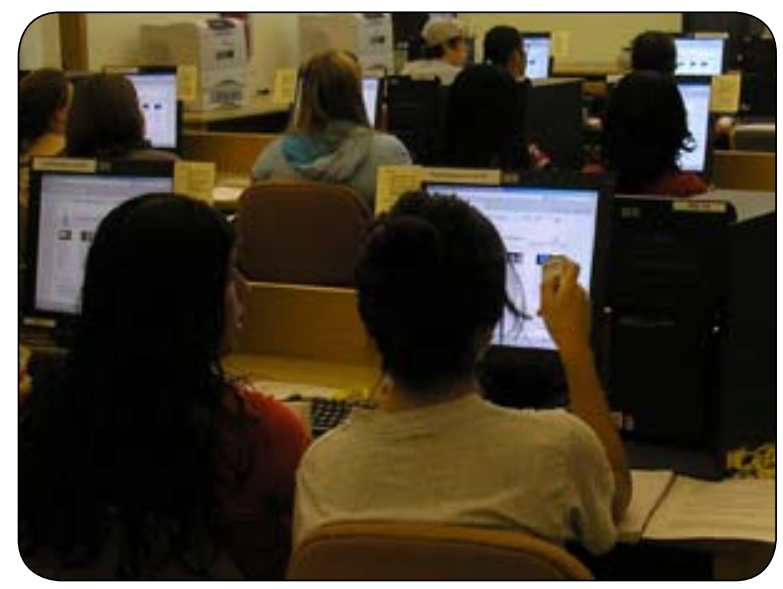

High school debaters give the clickers a workout during a hands-on instructional session in the library's computer lab.

The idea of using practice questions was to help calm fears. Some of the debaters were away from home for the first time. They were in a new learning environment and probably felt somewhat 
overwhelmed. Using practice clicker questions at the beginning of class helped the students feel more comfortable and, as one debater observed, the "ice-breaker" questions were fun and interesting!

During the instructional session, students used clickers to respond to questions. Students were asked about LC Subject Headings and call numbers, locations of specific titles that are located in the stacks or online, and search strategies such as the use of Boolean operators and truncation. In the majority of cases, the students did well on the questions, but most questions had a few incorrect responses. The benefit of asking for the answers through clicker responses is that the instructor gets immediate feedback on problem areas and can revisit content in response to incorrect answers.

How did the debaters react toward the clickers? Data about student perceptions of the clickers were collected from a brief evaluation form which 36 debaters turned in at the end of the workshop. A majority of the debaters $(86 \%)$ agreed or strongly agreed that they enjoyed using the clickers to respond to questions. Approximately $44 \%$ of the debaters indicated that using the clickers to respond to questions allowed them to better understand the material, while $39 \%$ were undecided.

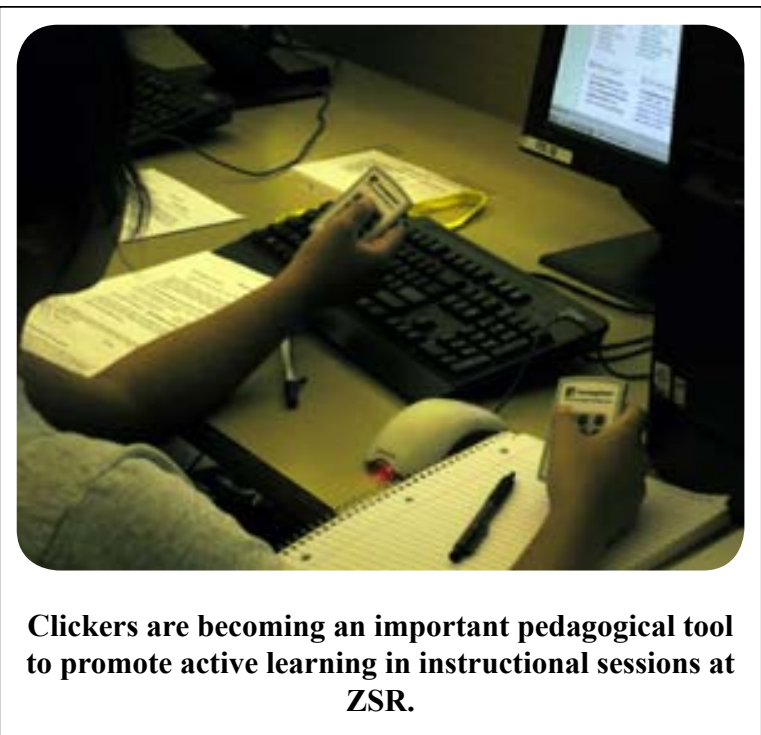

president. The planning committee (Blue Sky) solicited input from library staff on our building, our services, our collections, and many other topics. The Blue Sky committee then developed lists of ideas and suggestions in each of these areas.

In order to get an idea of how our staff would prioritize these ideas and suggestions, we had a library-wide staff meeting where the clickers were used. Our director very much wanted to hear equally from every staff member and since the clickers are anonymous and do not discriminate against the quieter people on the staff, they seemed the perfect option for feedback.
The debaters were also asked to list some advantages and disadvantages of using the clickers in the classroom. Interestingly, debaters' comments were very similar to those of the LIB 100 students. For instance, some of the advantages that the debaters mentioned were the anonymous feature; fun; quick response time; everyone participates; and the clickers create a more interactive environment. One debater commented, "It provides a quick glance of the classes' knowledge to compare to yourself." Disadvantages included having to press several times to ensure your response is counted; hard to press; easily broken or stolen. Several students remarked that the clickers discourage note taking. One student noted, "Sometimes I would accidentally press [the] wrong button."

One reason why the debaters were very enthusiastic about the clickers is that these "students of the twenty-first century have grown up using computer games for learning and entertainment." And as one debater mentioned, the clickers "make the instructional session less boring. Now the lesson is an interactive game." When asked if the Z. Smith Reynolds Library should continue to use clickers in library instructional sessions, the debaters overwhelmingly answered in the affirmative.

\section{Soliciting Feedback from Staff}

One of the driving forces behind investigating the clickers was our director's desire to get staff feedback on various topics. In the Fall of 2006 and the Spring of 2007, the ZSR Library was in the midst of a strategic planning process that was part of the larger university's strategic planning taking place under our new

\section{Taking the Clickers on the Road}

In addition to being an effective tool in the classroom, clickers can also offer presenters an excellent opportunity to learn about their audiences and to adjust a presentation accordingly. When speaking at a conference or at another institution, the presenter is often unsure what the audience knows about the topic and where it stands on issues surrounding the topic. Beginning a presentation with clicker questions about the topic can give the speaker insight into the audience and an opportunity to adjust the presentation to better meet its needs.

An example of this approach is the Wake Forest University/ Georgia Institute of Technology joint presentation on gaming in academic libraries at the first ALA Gaming Symposium in July of 2007. This was the first conference of its type, and as such, the presenters knew even less than usual about the content the audience expected from this presentation. To solve that, we asked four questions to establish the demographics of the group and learn more about needs.

Through four clicker questions in three minutes, it was determined that $86 \%$ of the participants were from academic libraries, $80 \%$ had not yet hosted a gaming event in the library, $60 \%$ were considering hosting such an event, and $40 \%$ of those would host such an event as a marketing tool for their libraries. As a result of these questions we were able to tailor the presentation on the spot to focus on the logistics of hosting a game night rather than focusing on why libraries would host game nights. This was an easy transition to make that gave our audience more value. 
Another example of using clickers to enhance a presentation also involves gaming in academic libraries. When presenting "How to Get Game: Conducting Gaming Events in an Academic Library" at East Carolina University, the Manager of Technology Training used clickers to determine how many members of the audience were gamers or interested in video games. Only 24\% identified themselves as gamers and $49 \%$ responded, "What's a Gamer?" Fifty-eight percent said they were there to learn about gaming and how to host an event. Realizing there was audience of people new to gaming but interested in the topic, the presenters could adjust accordingly, attempting to include information that would generate interest in gaming among the other $38 \%$.

For clickers to be effective, speakers must be willing to adapt their presentations quickly to meet the needs of the audience. Additionally, they must be adept at troubleshooting potential software or hardware issues with the clickers in order to ensure a smooth presentation. If they are willing to make this extra effort, clickers can enhance a presentation and offer more value to the audience.

\section{Committing to Clickers}

As with the use of any new educational device, instructor feedback regarding the perceived impact of the new technology on student learning and retention is important. Before instructors commit to incorporating novel instructional approaches into their classrooms, they must see the potential payoffs in order to decide if the new tech tool will have an impact on student performance. An important part of the teaching process involves designing and developing instructional content; if instructors perceive that a new educational device will disrupt or hinder their efforts, they may abandon the idea of experimenting with a teaching tool. As clicker enthusiasts know, it takes time to develop good clicker questions and organize effective PowerPoint presentations.

Another clicker issue to consider is class time. If an instructor includes four or five clicker questions, it "will probably take an additional 10 minutes of class time, at a minimum."' Instructors who teach 50-minute classes may find that they cannot cover as much material when using the clickers. During the live presentation, these instructors may find they are tweaking their lectures and at the same time inadvertently developing a new set of instructional strategies to improve and support clicker technology.

Our clicker experience has demonstrated that when there are fewer students, clicker response time is very fast. During the summer, there were 11 debaters in the first class and 26 in the second class. In the first class, the response time was great. However, with more students in the second class, the response time was a little slower. In fact, several debaters in the second class noted that the lesson had to be delayed so that everyone could respond. Instructors will need to decide how long to wait for students to answer the questions, as slow response time will impact the timing and delivery of information in the instructional session.

Although some instructors have encountered a few problems in using clickers, most of the LIB100 instructors continue to use the clickers and so far the novelty has not worn off. Instructors are finding that the clickers help the students to stay focused on the lecture. In addition, librarians who teach information literacy classes using clickers have a better understanding of areas where students are having difficulty grasping a particular concept or skill. If $80 \%$ of the students miss a question on Boolean operators, the librarian can go back and cover the concept again. Another tactic that has proven successful is to give students a question or two at the beginning of the class about the material about to be covered. In almost all cases, a large percentage of students will answer the questions incorrectly, thus perhaps making them pay more attention to the content of the class. And if all of the students happen to answer them correctly, then class content can be altered to cover new topics.

Our least successful use of clickers occurred in the Wake Forest University freshman orientation program, "Technology@WFU." In this program, students receive information about computing at Wake Forest. Clicker questions were incorporated into the PowerPoint program after each section of content to see if the students got the message we were conveying. Sixty clickers were passed out among the 550 students in each of the two sections of "Technology@WFU." Each student with a clicker answered one question and passed the clicker on to another student who answered the next question. This effort did not engage the students as anticipated, perhaps because of a lack of clickers for all students.

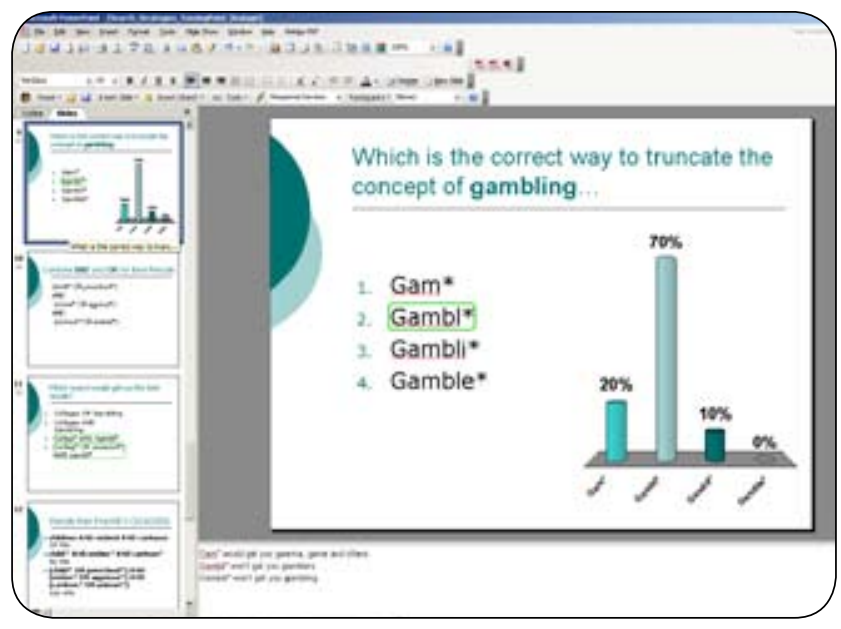

\section{Here is an example of a multiple choice question and the results you get. Questions can be True/False, Multiple Choice, Likert, Multiple Answer, or even Analogies or Word Scrambles as Ice Breakers.}

\section{Clicking Pointers}

The integration of the clickers into a library session can be an exciting experience for both instructors and students. Here are a few points to keep in mind:

- Do your homework. Be sure to understand who in your organization will be using the clickers and how comfortable they are with technology. Then investigate the various vendors and find the best match for you. From a user perspective, clickers work pretty much the same from vendor to vendor. The major differences lie in the back-end interfaces; thus the highest learning curve is for the people creating the clicker presentations. Clicker systems provide various levels of functionality and with that functionality come more complicated processes on the instructors' end. Be sure instructors attend the demos and have input into the decision. 
- Build on success. Examine what you have traditionally done in the classroom. What worked? Don't be afraid to experiment with new approaches. Innovative instruction sometimes requires thinking outside of one's comfort zone.

- Create a plan of action and start early. Redesigning and developing new instructional content takes time. Coming up with good questions to use and organizing the PowerPoint slides are crucial for an effective presentation. One successful strategy we have employed is the sharing of PPT presentations with clicker slides among instructors. This gives instructors the ability to focus on the content and not the creation of new clicker slides. It is also critical to allow instructors time to practice their PowerPoint presentations and to receive feedback from other librarians if they are uncomfortable using clickers for the first time in a real classroom setting.

- Seek tech support along the way. If you are not tech savvy, team up with tech people. Have someone come at the beginning of class to make sure that all of the equipment is working. Also, before you launch into your presentation, do a simple test to ensure that both the receiver and the clickers are working. Our system requires running the "restart wizard" each time a different receiver is used. Taking time to check out potential tech problems will help with point five.

- Calm fears. This point impacts both librarians and students. Naturally, instructors may be nervous during the first presentation with new technology. Keep a positive attitude and project this to your audience.

- Consider using practice clicker questions at the beginning of a class or a meeting. It is a great way to grab an audience's attention and involve it in the upcoming presentation while ensuring your clickers and software are working.

\section{Conclusion}

Based on our experiences, the clickers are definitely a hit with our staff and our students. The enthusiastic assessment by WFU and high school students suggests that clickers can be a valuable teaching tool. As new technologies impact higher education, librarians must seize the opportunity to investigate and evaluate the most appropriate ones for delivery of information in order to enhance the teaching and learning process.
At ZSR we continue to experiment with advanced functionality such as assigning clickers to individuals for assessment purposes and with using them with groups for competitions. We would also like to include clickers in one-shot library instruction sessions. A few well-placed questions during these sessions may make students more attentive and engaged in the content. We continue to look for ways we can incorporate the clickers into staff meetings, committee work, and other in-house projects across the library. All in all, we have been extremely pleased with the clickers and hope to continue to find new and innovative ways to incorporate them into our services.

\section{References}

${ }^{1}$ Christina Hoffman and Susan Goodwin, "A Clicker for your Thoughts: Technology for Active Learning," New Library World 107, no. 9/10 (2006): 422-433.

${ }^{2}$ Wenxian Zhang, "Building Partnerships in Liberal Arts Education: Library Team Teaching," Reference Services Review 29, no. 2 (2001): 141-149.

${ }^{3}$ Gary Roberts, "Instructional Technology That's Hip High-Tech," Computers in Libraries 25 (November/December 2005): 26-28.

${ }^{4} \mathrm{Jim}$ Tweeten et al., "Successful Clicker Standardization," EDUCAUSE Quarterly 30, no.\#4 (2007):63-67. http:// connect.educause.edu/Library/EDUCAUSE+Quarterly/ SuccessfulClickerStandard/45543 (February 11, 2008).

${ }^{5}$ Margie Martyn, "Clickers in the Classroom: An Active Learning Approach," EDUCAUSE Quarterly 30, no.\#2 (2007): 71-74. http://connect.educause.edu/Library/EDUCAUSE+Quarterly/ ClickersintheClassroomAnA/40032 (February 11, 2008).

${ }^{6}$ Tweeten et al., 66.

Bobbie L. Collins (collinsb@wfu.edu) is the Social Sciences Reference Librarian; Rosalind Tedford (tedforrl@wfu.edu) is the Information Literacy Librarian; and H. David “Giz” Womack (womack@wfu.edu) is the Manager of Technology Training, at Wake Forest University.

\section{Submission requirements for North Carolina Libraries}

Electronic file of article.

- Word orWordPerfect

- Windows/Mac format acceptable (No UNIX or CP/M please)

- Delivered via email

We use the Chicago manual of style (15th edition, 2003).

We have a rolling deadline, articles are juried when received.

Publication of approved articles is in about 3-9 months depending on space available.

Please contact Ralph Scott scottr@ecu.edu for information. 